\title{
Effect of Work Intensity on Time Delay in Mediation of Ventilation by Arterial Carbon Dioxide During Recovery From Impulse Exercise
}

\author{
R. AFROUNDEH ${ }^{1}$, T. ARIMITSU ${ }^{2}$, R. YAMANAKA ${ }^{2}$, C. S. LIAN ${ }^{2}$, K. SHIRAKAWA ${ }^{2}$, \\ T. YUNOKI ${ }^{3}$, T. YANO ${ }^{3}$
}

${ }^{1}$ Department of Sport Science and Physical Education, Payame Noor University, Tehran, Iran, ${ }^{2}$ Graduate School of Education, Hokkaido University, Sapporo, Japan, ${ }^{3}$ Department of Human Developmental Sciences, Faculty of Education, Hokkaido University, Sapporo, Japan

Received August 1, 2013

Accepted January 23, 2014

On-line April 3, 2014

\section{Summary}

Time delay in the mediation of ventilation ( $\dot{\mathrm{V} E}$ ) by arterial $\mathrm{CO}_{2}$ pressure $\left(\mathrm{PaCO}_{2}\right)$ was studied during recovery from short impulse-like exercises with different work loads of recovery. Subjects performed two tests including 10-s impulse like exercise with work load of 200 watts and 15-min recovery with 25 watts in test one and 50 watts in test two. $\dot{V} E_{\text {, end tidal }} \mathrm{CO}_{2}$ pressure $\left(\mathrm{PETCO}_{2}\right)$ and heart rate (HR) were measured continuously during rest, warming up, exercise and recovery. $\mathrm{PaCO}_{2}$ was estimated from $\mathrm{PETCO}_{2}$ and tidal volume $\left(\mathrm{V}_{\mathrm{T}}\right)$. Results showed that predicted arterial $\mathrm{CO}_{2}$ pressure $\left(\mathrm{PaCO}_{2}\right.$ pre $)$ increased during recovery in both tests. In both tests, $\dot{V} E$ increased and peaked at the end of exercise. VE decreased in the first few seconds of recovery but started to increase again. The highest correlation coefficient between $\mathrm{PaCO}_{2}$ pre and $\dot{V} E$ was obtained in the time delay of $7 \mathrm{~s}(\mathrm{r}=0.854)$ in test one and in time delays of $6 \mathrm{~s}$ $(r=0.451)$ and $31 \mathrm{~s}(r=0.567)$ in test two. HR was significantly higher in test two than in test one. These results indicate that $\mathrm{PaCO}_{2}$ pre drives $\dot{V} \mathrm{E}$ with a time delay and that higher work intensity induces a shorter time delay.

\section{Key words}

Arterial $\mathrm{CO}_{2}$ pressure - Impulse-like exercise - Time delay • Ventilation

\section{Corresponding author}

T. Yano, Department of Human Development Science, Faculty of Education, Hokkaido University, Kita-11, Nishi-7, Kita-ku, Sapporo 060-0811, Japan. Tel. and Fax: +81-11-706-5090. E-mail: yano@edu.hokudai.ac.jp

\section{Introduction}

It is well known that rapid responses to respiratory stimuli, such as disturbances in $\mathrm{O}_{2}$ and $\mathrm{CO}_{2}$ tension, are mediated by peripheral chemoreceptors, and it has been widely argued that the most important role in peripheral chemoreception is played by the carotid body (Prabhakar and Peng 2004). Several studies in humans support the role of peripheral chemoreception in the regulation of breathing during exercise (Wasserman et al. 1975, Griffiths et al. 1980, Whipp and Wasserman 1980, Oren et al. 1982). The involvement of peripheral chemoreceptors was suggested in early studies in which the effects of a sudden load of hypercapnic venous blood on ventilation ( $\dot{\mathrm{VE}})$ were examined by using circulatory occlusion. In those studies, a time lag between arrival of the hypercapnic blood at the lungs and onset of the ventilatory response was observed and it was concluded that $\dot{\mathrm{VE}}$ is not mediated by assumed rapidly responding chemoreceptors located in the pulmonary system but rather by peripheral and medullary chemoreceptors (Hildebrandt et al. 1979, Stanley et al. 1987). These chemoreceptors are stimulated by arterial potassium $\left(\mathrm{K}^{+}\right)$ (Paterson 1992), circulating catecholamine (Prabhakar and Peng 2004), lactic acid and arterial carbon dioxide pressure $\left(\mathrm{PaCO}_{2}\right)$ (Cross et al. 1979, Band et al. 1980). During recovery from exercise, the levels of catecholamine and $\mathrm{K}^{+}$rapidly recover to the rest values (Clement et al. 1996); however, lactic acid in the blood persists for a long time and stimulates peripheral chemoreceptors (Knuttgen et al. 1972, Clement et al. 
1992). To eliminate the influence of lactic acid on VE, we planned a short impulse-like exercise $(10 \mathrm{~s})$ that does not cause an increase in $\mathrm{H}^{+}$and provides a condition in which only the effect of $\mathrm{PaCO}_{2}$ on $\mathrm{VE}$ during recovery from exercise can be examined. Despite previous studies in which circulatory occlusion was used to create hypercapnic venous blood, short impulse-like exercise produced an increase in the level of $\mathrm{PaCO}_{2}$ during recovery in the present study.

The transition from a chemoreceptor stimulus $\left(\mathrm{PaCO}_{2}\right.$ in the present study) to alveolar VE occurs via a pathway that includes chemoreceptors that sense the signal, the central nervous system that processes it, and the respiratory muscles that translate it into alveolar ventilation (Duffin 2010). Therefore, the hypothesis that VE responds with a time delay to the stimulation of chemoreceptors by $\mathrm{PaCO}_{2}$, seems plausible. If this hypothesis holds true, the relationship between $\mathrm{PaCO}_{2}$ and $\dot{\mathrm{VE}}$ should be improved by considering the time delay. We applied a cross correlation method to determine correlation coefficients between $\mathrm{PaCO}_{2}$ and $\dot{\mathrm{VE}}$ in different time delays. Furthermore, the time delay between $\mathrm{PaCO}_{2}$ and $\dot{\mathrm{VE}}$ indicates that this is sufficient time for $\mathrm{CO}_{2}$-enriched blood to reach the peripheral or central chemoreceptors. Greater blood flow should cause $\mathrm{CO}_{2}$-enriched blood to reach the chemoreceptors faster and reduce the time delay between $\mathrm{PaCO}_{2}$ and $\mathrm{VE}$. It has been reported that cardiac output and leg blood flow increased in parallel with increase in exercise intensity (Calbet et al. 2007). Thus, a higher work intensity should cause an increase in blood flow and consequently the time delay between $\mathrm{PaCO}_{2}$ and VE should be shortened. In this study, two tests with different work loads during recovery from impulse-like exercise were carried out to examine the effect of work intensity on the time delay between $\mathrm{PaCO}_{2}$ and ventilatory response.

\section{Methods}

\section{Subjects}

Eight healthy males participated in this study. The subjects' mean age, height and body weight were $21.3 \pm 1.5$ (SD) years, $172.9 \pm 6.2 \mathrm{~cm}$ and $67.9 \pm 9.7 \mathrm{~kg}$, respectively. Each subject signed a statement of informed consent following a full explanation regarding the nature of the experiment. The Ethics Committee of Hokkaido University Graduate School of Education approved the present study.
Design

Each subject came to our laboratory three times on separate days and performed a pre-test and two main tests consisting of one impulse-like exercise by a bicycle ergometer (Ergometer 232 CXL, Combi, Tokyo, Japan). Subjects were instructed to refrain from intense physical exercise, drinking alcohol and taking caffeine for $24 \mathrm{~h}$ prior to the tests. None of the subjects had a smoking habit.

\section{Experimental protocol}

In both tests, after resting for $1 \mathrm{~min}$ on the bicycle seat, subjects performed 5-min warming up with 25 watts work load followed by 10 -s impulse-like exercise with 200 watts work load. After impulse-like exercise, they had 15 -min active recovery with 25 watts work load in test one and with 50 watts work load in test two.

\section{Measurements and determinations}

Blood was sampled from fingertips at rest and after $1 \mathrm{~min}$ and $5 \mathrm{~min}$ during the recovery period in the pre-test to be checked for lactate concentration ( $\mathrm{La}^{-}$) by using a Blood Lactate Test Meter. Each subject's hand was pre-warmed in $40-45^{\circ} \mathrm{C}$ water prior to each sampling in order to arterialize capillary blood. It has been shown that such blood samples might not accurately reflect arterial $\mathrm{O}_{2}$ pressure but can closely reflect arterial $\mathrm{CO}_{2}$ and $\mathrm{pH}$ (Zavorsky et al. 2007).

Data on respiration gas exchange were obtained breath-by-breath using a respiratory gas analyzer (AE-280S, Minato Medical Science, Osaka, Japan). Ventilation (VE) was measured by a hot-wire flow meter, and the flow meter was calibrated with a syringe of known volume (2 liters). $\mathrm{O}_{2}$ and $\mathrm{CO}_{2}$ concentrations were measured by a zirconium sensor and infrared absorption analyzer, respectively. The gas analyzer was calibrated by known standard gas $\left(\mathrm{O}_{2}: 15.17 \%, \mathrm{CO}_{2}: 4.9 \%\right)$. Heart rate (HR) was recorded using a heart rate monitor installed in the respiratory gas analyzer. $\dot{\mathrm{VE}}$, end tidal $\mathrm{CO}_{2}$ partial pressure $\left(\mathrm{PETCO}_{2}\right)$ and $\mathrm{HR}$ were measured continuously during rest, warming up, exercise, and recovery periods. Breath-by-breath data was transformed into $1 \mathrm{~s}$ data using KaleidaGraph software. We applied this method for data of $\mathrm{VE}, \mathrm{PETCO}_{2}, \mathrm{HR}$ and tidal volume $\left(\mathrm{V}_{\mathrm{T}}\right)$ in each subject and averages of all subjects' data were used for analyzing.

To obtain continuous data of $\mathrm{PaCO}_{2}$, it was estimated from $\mathrm{PETCO}_{2}$ and $\mathrm{V}_{\mathrm{T}}$ using the formula of 
Jones et al. (1979):

Predicted $\mathrm{PaCO}_{2}\left(\mathrm{PaCO}_{2}\right.$ pre $)=5.5+0.90 \mathrm{PETCO}_{2}-0.0021 \mathrm{~V}_{\mathrm{T}}$.

\section{Statistical analysis}

Results are presented as means \pm standard deviations (SD). One-way ANOVA for repeated measures was used to examine the time effect in each test. If $\mathrm{F}$ ratios were significant, the Dunnet post-hoc test was used for comparison. A paired t-test was used to examine significant differences between the two tests. A value of $\mathrm{p}<0.05$ was regarded as statistically significant.

\section{Results}

Arterialized $\mathrm{La}^{-}$level did not change during recovery at any time point versus rest time $(p>0.05)$ in the pre-test. Mean values and SD of $\mathrm{La}^{-}$are presented in Table 1.

Table 1. Mean values and SD of arterialized blood lactate at rest and during recovery from 200 watts impulse-like exercise in the pre-test.

\begin{tabular}{lccc} 
& \multirow{2}{*}{ Rest } & \multicolumn{2}{c}{ Recovery } \\
\cline { 3 - 4 } & & $\mathbf{1}$ $\mathbf{m i n}$ & $\mathbf{5} \mathbf{~} \mathbf{m}$ \\
\hline Mean & 1.15 & 1.23 & 1.0 \\
SD & 0.29 & 0.43 & 0.13 \\
\hline
\end{tabular}

Arterialized blood lactate levels were not significantly different from the rest value during recovery $(p>0.05)$.

In both tests, $\mathrm{PaCO}_{2}$ pre increased slowly during exercise and decreased in the first few seconds of recovery; however, it started to increase again and peaked at $19 \mathrm{~s}$ of recovery in test one $(44.46 \pm 1.88 \mathrm{~mm} \mathrm{Hg})$ and at $23 \mathrm{~s}$ of recovery in test two $(44.65 \pm 2.42 \mathrm{~mm} \mathrm{Hg})$. In test one, $\mathrm{PaCO}_{2}$ was significantly higher than the warming-up value $(40.71 \pm 1.65 \mathrm{~mm} \mathrm{Hg})$ from $14 \mathrm{~s}$ until $28 \mathrm{~s}$ of recovery $(\mathrm{p}<0.05)$ (Fig. 1 , upper panel). In test two, $\mathrm{PaCO}_{2}$ was significantly higher than the warming-up value $(39.79 \pm 2.14 \mathrm{~mm} \mathrm{Hg})$ from $11 \mathrm{~s}$ until $50 \mathrm{~s}$ of recovery $(p<0.05)$ (Fig. 1, lower panel). There was no significant difference between the two tests in $\mathrm{PaCO}_{2}$ pre at rest, during warming up, during exercise and during recovery $(\mathrm{p}>0.05)$.

$\dot{V} E$ increased during exercise and peaked at the end of exercise in test one and test two
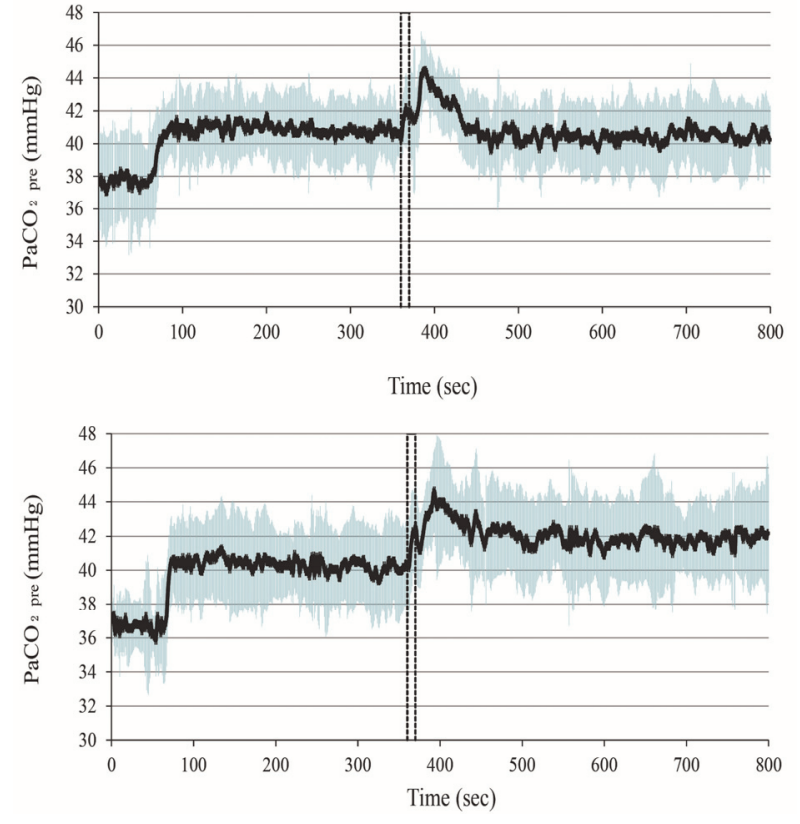

Fig. 1. Changes in predicted arterial carbon dioxide partial pressure $\left(\mathrm{PaCO}_{2}\right.$ pre $)$ during 200 watts impulse-like exercise and recovery from 200 watts impulse-like exercise with work load of 25 watts in test one (upper panel) and work load of 50 watts in test two (lower panel). The vertical dashed line bar indicates exercise time. Data presented are means \pm SD.

(31.89 $\pm 3.911 . \mathrm{min}^{-1}$ and $31.22 \pm 2.621 . \mathrm{min}^{-1}$ respectively). In test one,VE showed a second rise during recovery and peaked at $26 \mathrm{~s}$ of recovery $\left(31.57 \pm 1.411 . \mathrm{min}^{-1}\right)$. After this peak, VE decreased gradually and recovered to the warming-up value. It was significantly higher than the warming-up value $\left(22.26 \pm 2.651 . \mathrm{min}^{-1}\right)$ from $8 \mathrm{~s}$ of exercise until $4 \mathrm{~s}$ of recovery $(\mathrm{p}<0.05)$. It decreased and was not significantly different from the warming-up value from $5 \mathrm{~s}$ to $13 \mathrm{~s}$ of recovery $(\mathrm{p}>0.05)$. However, it increased again and was significantly higher than the warming-up value from $14 \mathrm{~s}$ until $90 \mathrm{~s}$ of recovery $(\mathrm{p}<0.05)$ (Fig. 2, upper panel). In test two, VE showed two peaks during recovery: the first one at $26 \mathrm{~s}$ of recovery $\left(31.81 \pm 2.881 . \mathrm{min}^{-1}\right)$ and the second peak at $68 \mathrm{~s}$ of recovery $\left(34.44 \pm 2.181 . \mathrm{min}^{-1}\right)$. After this peak, VE decreased but did not recover to the warming-up value. It was significantly higher than the warming-up value $\left(23.44 \pm 2.211 . \mathrm{min}^{-1}\right)$ from $9 \mathrm{~s}$ of exercise until $5 \mathrm{~s}$ of recovery $(\mathrm{p}<0.05)$. From $6 \mathrm{~s}$ to $15 \mathrm{~s}$ of recovery, it decreased and was not significantly different from the warming-up value $(p>0.05)$. VE increased again and was significantly higher than the warming-up value from $16 \mathrm{~s}$ until the end of the test (Fig. 2, lower panel). There was no significant difference in VE level between the two tests at rest, during warming up, during exercise and the first $42 \mathrm{~s}$ of recovery; however, VE level was significantly higher in 

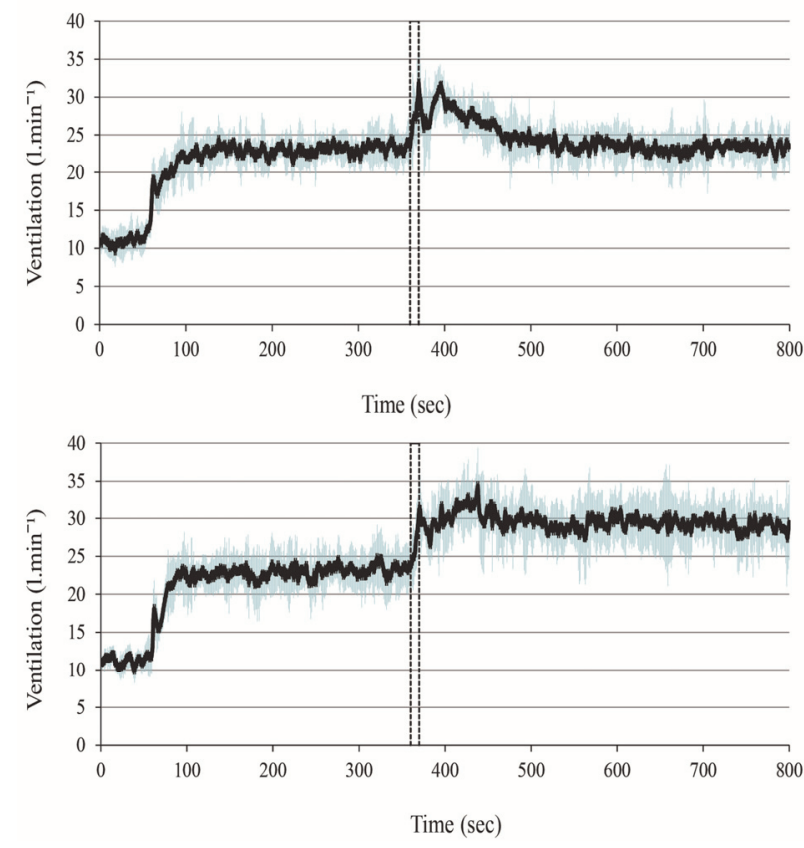

Fig. 2. Changes in ventilation ( $\dot{\mathrm{V} E})$ during 200 watts impulse-like exercise and recovery from 200 watts impulse-like exercise with work load of 25 watts in test one (upper panel) and work load of 50 watts in test two (lower panel). The vertical dashed line bar indicates exercise time. Data presented are means \pm SD.

test two than in test one from $43 \mathrm{~s}$ until the end of recovery $(\mathrm{p}<0.05)$.

We obtained a cross correlation between $\mathrm{PaCO}_{2}$ pre and $\dot{\mathrm{VE}}$ by using average data for all subjects during recovery from exercise in both tests. As can be seen in the upper panel of Figure 3, the highest correlation coefficient was observed at the time delay of $7 \mathrm{~s}$ between $\mathrm{PaCO}_{2}$ pre and $\mathrm{VE}$ in test one $(\mathrm{r}=0.854)$. In test two, although correlation coefficients were not high, two peaks were observed at time delays of $6 \mathrm{~s}(\mathrm{r}=0.451)$ and $31 \mathrm{~s}(\mathrm{r}=0.567)$.

In both tests, heart rate (HR) increased during exercise and peaked at the end of exercise. HR started to decrease during recovery. In test one, it was significantly higher than the warming-up value $(85.16 \pm 8.45$ beats. $\mathrm{min}^{-1}$ ) from the start of exercise until $33 \mathrm{~s}$ of recovery $(p<0.05)$; however, it was significantly higher than the warming-up value $\left(85.24 \pm 9.21\right.$ beats. $\left.\mathrm{min}^{-1}\right)$ from the start of exercise until the end of recovery in test two. HR was not significantly different between the two tests at rest, during warming up, during exercise and the first $30 \mathrm{~s}$ of recovery; however, after this time point it was significantly higher in test two than in test one during recovery $(p<0.05)$. Figure 4 shows these changes in HR (test one: upper panel, test two: lower panel).
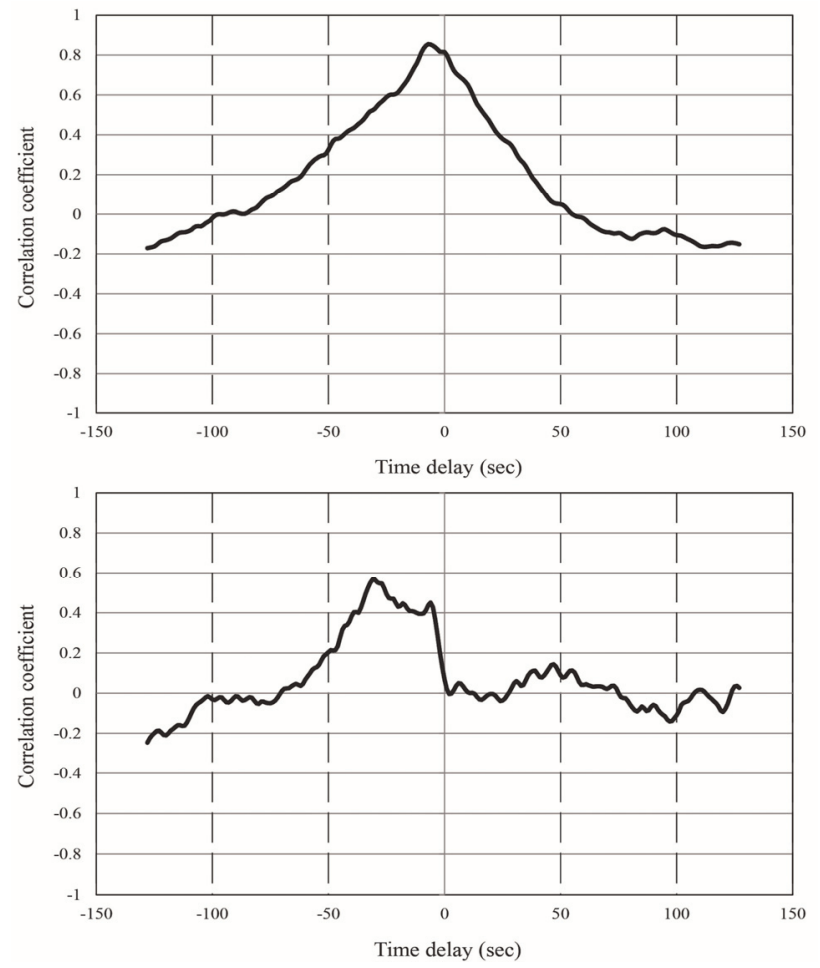

Fig. 3. Cross correlation between ventilation ( $\dot{\mathrm{V}} \mathrm{E})$ and predicted arterial carbon dioxide partial pressure $\left(\mathrm{PaCO}_{2}\right.$ pre $)$ during recovery from 200 watts impulse-like exercise in test one (upper panel) with work load of 25 watts during recovery and in test two (lower panel) with work load of 50 watts during recovery.
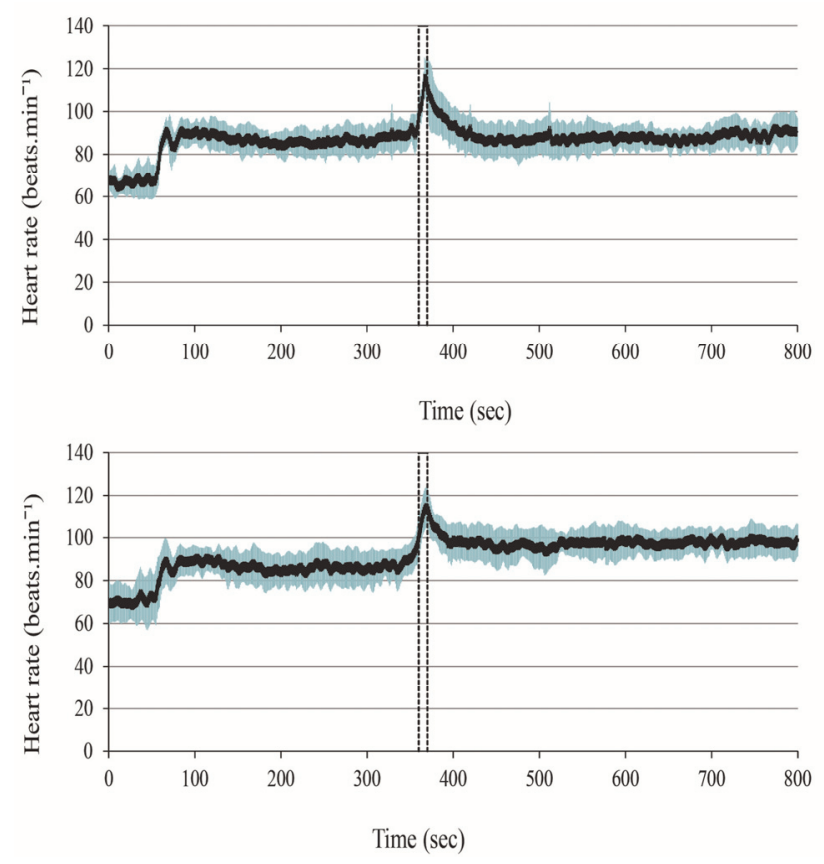

Fig. 4. Changes in heart rate (HR) during 200 watts impulse-like exercise and recovery from 200 watts impulse-like exercise with work load of 25 watts in test one (upper panel) and work load of 50 watts in test two (lower panel). The vertical dashed line bar indicates exercise time. Data presented are means \pm SD. 


\section{Discussion}

The subjects in the present study performed two tests including an impulse-like exercise with work load of 200 watts and duration of $10 \mathrm{~s}$ followed by active recovery with 25 watts work load in test one and 50 watts work load in test two. This short impulse-like exercise did not cause an increase in $\mathrm{La}^{-}$level (Table 1); however, increases in $\mathrm{PaCO}_{2}$ pre (predicted from $\mathrm{PETCO}_{2}$ and $\mathrm{V}_{\mathrm{T}}$ ) were observed during recovery time in both tests. VE increased and peaked at the end of exercise, after which it dropped slightly at the starting point of recovery. This initial fast increase (phase 1) in ventilatory response is induced by neural signals from mechanical receptors in working muscle (Turner 1991). When the work intensity decreases from 200 watts in exercise to 25 watts and 50 watts in recovery time, the number of these signals or the amount of them may decrease at the end of exercise and cause an abrupt decline in VE response. Being consistent with results of previous studies (Haouzi et al. 2001, 2002) a second rise in VE occurred after the end of exercise in both tests. This further drive and the second peak of $\dot{\mathrm{VE}}$ might be due to $\mathrm{PaCO}_{2}$ as it increased during recovery in both tests and the results of our previous study indicated that $\mathrm{PaCO}_{2}$ drives $\mathrm{VE}$ during recovery from impulse-like exercise without metabolic acid (Afroundeh et al. 2013). We obtained a cross correlation between $\mathrm{PaCO}_{2}$ pre and $\mathrm{VE}$ during recovery from both tests, and the results showed that in test one there is a high correlation coefficient $(\mathrm{r}=0.854)$ between $\mathrm{PaCO}_{2}$ pre and $\mathrm{VE}$ in a time delay of $7 \mathrm{~s}$. In test two, two peaks in the correlation coefficient (though not high) were observed in the relationship between $\mathrm{PaCO}_{2}$ pre and $\dot{\mathrm{VE}}$. The first peak in correlation coefficient was obtained in a time delay of $6 \mathrm{~s}(\mathrm{r}=0.451)$, which is shorter than the time delay in test one ( $7 \mathrm{~s})$, and the second peak in correlation coefficient was obtained in a time delay of $31 \mathrm{~s}(\mathrm{r}=0.567)$. The results of a study performed by Gonzalez et al. (1977), in which they injected chemical stimuli into the right heart of resting dogs and measured the transport time to the carotid sinus and the time of onset of the ventilatory response, showed that the onset of ventilatory response to the chemical stimuli occurred 5 to $12 \mathrm{~s}$ after injection, and coincided with the arrival of substances at the carotid sinus. The only time delay obtained in test one ( $7 \mathrm{~s}$ ) and the first time delay obtained in test two $(6 \mathrm{~s})$ in the present study are close to the time delay obtained in the study by Gonzalez et al. (1977). Therefore we believe that the first rise in $\dot{\mathrm{VE}}$ during recovery from both tests in the present study is due to the stimulation of carotid bodies by $\mathrm{PaCO}_{2}$. The higher HR (Fig. 4) and presumably higher cardiac output in test two enable faster transfer of $\mathrm{PaCO}_{2}$ to carotid bodies and consequently shorter time delay between $\mathrm{PaCO}_{2}$ pre and VE. It should be noted that the chemoreception mechanism is not the only factor affecting VE during recovery in the present tests. The subjects experienced active recovery in both tests and the effect of mechanical receptors therefore exists during recovery from both tests, though the effect is small in test one with only 25 watts work load. Thin fiber afferents (i.e. groups III and IV) in working muscles, which are thought to respond to mechanical and metabolic stimuli (McCloskey and Mitchell 1972, Kaufman et al. 1983) and also to respond to mechanical distension of the peripheral vascular network and change in volume of blood in the venular system (Haouzi et al. 2001), have been reported to be involved in the $\mathrm{VE}$ response during recovery from exercise (Fukuba et al. 2007). If we assume that cardiac output was higher in test two, it can be interpreted that the load imposed on venous return was much higher in test two than in test one and therefore the contribution of the effect of thin fiber afferents on $\mathrm{VE}$ was more in test two. The greater contribution of the effect of thin fiber afferents on $\dot{\mathrm{VE}}$ in test two may result in the lower contribution of the effect of $\mathrm{PaCO}_{2}$ on $\dot{\mathrm{VE}}$ and in lower $r$ values in the relationship between $\mathrm{PaCO}_{2}$ pre and VE. On the other hand, although higher $\mathrm{HR}$ and higher cardiac output make the transfer of $\mathrm{PaCO}_{2}$ to carotid bodies faster, they would also result in smaller contribution of the effect of $\mathrm{PaCO}_{2}$ on $\mathrm{VE}$.

The time constant for ventilatory increases due to activation of central chemoreceptors by hypercapnia is known to be between $65-180 \mathrm{~s}$ in humans (Tansley et al. 1998). This wide variation could be due to the different methodologies employed and also to the influence of peripheral chemoreception and particularly of the carotid body, which is known to play a part in modulating the central chemoresponsiveness to $\mathrm{CO}_{2}$ (Dahan et al. 1990, 2007). However, in the present study, the second and longer delay time (31 s) in the relationship between $\mathrm{PaCO}_{2}$ pre and $\dot{\mathrm{VE}}$ in test two is in agreement with the delayed time of ventilatory response to abrupt increases in $\mathrm{PETCO}_{2} \quad(30.9 \mathrm{~s})$ when only the central chemoreceptors could sense the increase in $\mathrm{CO}_{2}$ in dogs (Smith et al. 2006). In that study, extracorporeal perfusion of the vascularly isolated carotid sinus was used to maintain normal tonic activity of the carotid body 
while preventing it from sensing systemic changes in $\mathrm{CO}_{2}$. Therefore, it can be concluded that the second rise in VE during recovery in test two is due to stimulation of the central chemoreceptors by $\mathrm{PaCO}_{2}$ that requires diffusion from the blood through interstitial fluid. The reason for a second rise of $\dot{\mathrm{VE}}$ during recovery not being seen in test one is probably that the value of $\mathrm{PaCO}_{2}$ pre in this test was significantly higher than the warming-up value only for $14 \mathrm{~s}$ (from $14 \mathrm{~s}$ to $28 \mathrm{~s}$ during recovery), which is shorter than the required transferring time of $\mathrm{PaCO}_{2}$ to central chemoreceptors reported by Smith et al. in 2006 (30.9 s).

Except for the first $42 \mathrm{~s}$ of recovery, VE was significantly higher in test two than in test one until the end of the test even after recovery of $\mathrm{PaCO}_{2}$ pre. This difference is related to the effect of thin fiber afferents on $\dot{V E}$ as HR is higher in test two (Fig. 5). The reason why VE was not different between the two tests in the first $42 \mathrm{~s}$ of recovery despite different workloads is not clear. HR was also not different in the first $30 \mathrm{~s}$ of recovery. This suggests that the effect of thin fiber afferents on VE probably was not different between the two tests in the early recovery period. The sensitivity of peripheral mechanoreceptors may be temporarily blunted by highintensity exercise (impulse exercise), and in the early recovery period, the difference in mechanical stimulus between the two tests may therefore not have been sensed by the peripheral nerves.

In conclusion, the results of this study confirmed that $\mathrm{VE}$ responds with a time delay to stimulation of peripheral chemoreceptors by $\mathrm{PaCO}_{2}$ during active recovery from impulse-like exercise and that this time delay between $\mathrm{PaCO}_{2}$ pre and $\dot{\mathrm{VE}}$ is shorter when higher work intensity is applied during active recovery. There is a further time delay in the relationship between $\mathrm{PaCO}_{2}$ pre and $\dot{\mathrm{VE}}$ and a further peak in $\dot{\mathrm{VE}}$ during active recovery with higher work load that is related to stimulation of central chemoreceptors.

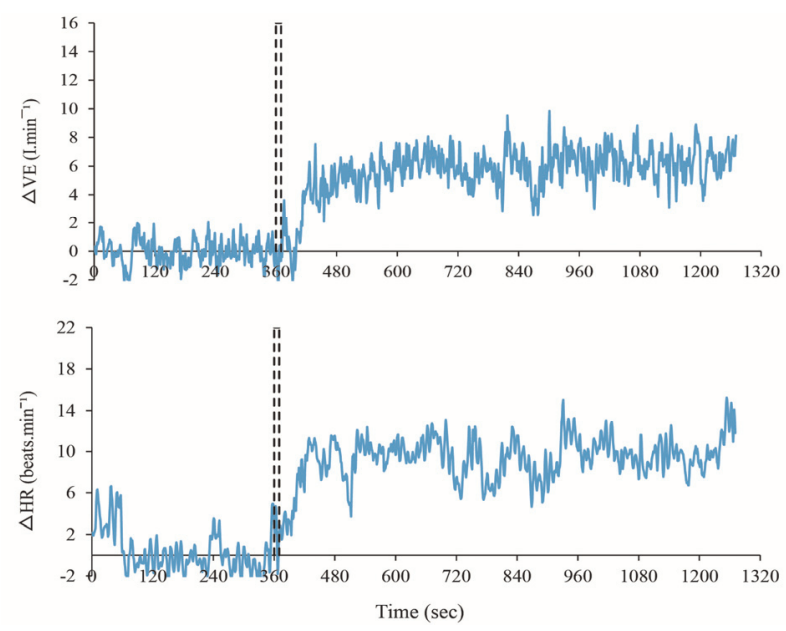

Fig. 5. Differences in the level of ventilation ( $\Delta \dot{\mathrm{V} E})$ (upper panel) and heart rate $(\Delta \mathrm{HR})$ (lower panel) at rest, during impulse-like exercise (200 watts) and during recovery between test one with 25 watts work load during recovery and test two with 50 watts work load during recovery. The vertical dashed line bar indicates exercise time.

\section{Conflict of Interest}

There is no conflict of interest.

\section{Acknowledgements}

This research was supported by JSPS KAKEN Grant Number 24500782. Grant-in Aid for Scientific Research.

\section{References}

AFROUNDEH R, ARIMITSU T, YAMANAKA R, SHIRAKAWA K, LIAN CS, YUNOKI T, YANO T: Relationship between ventilation and predicted arterial $\mathrm{CO}_{2}$ pressure during recovery from an impulse-like exercise without metabolic acidosis. Physiol Res 62: 387-393, 2013.

BAND DM, WOLFF CB, WARD J, COHRANE GM, PRIOR J: Respiratory oscillations in arterial carbon dioxide tension as a control signal in exercise. Nature 283: 84-85, 1980.

CALBET JA, GONZALEZ-ALONSO J, HELGE JW, SONDERGAARD H, MUNCH-ANDERSEN T, BOUSHEL R, SALTIN B: Cardiac output and leg and arm blood flow during incremental exercise to exhaustion on the cycle ergometer. J Appl Physiol 103: 969-978, 2007.

CLEMENT ID, BASCOM DA, CONWAY J, DORRINGTON KL, O'CONNOR DF, PAINTER R, PATERSON DJ, ROBBINS PA: An assessment of central-peripheral ventilatory chemoreflex interaction in humans. Respir Physiol 88: 87-100, 1992.

CLEMENT ID, PANDIT JJ, BASCOM DA, ROBBINS PA: Ventilatory chemoreflexes at rest following a brief period of heavy exercise in man. $J$ Physiol 495: 875-884, 1996. 
CROSS BA, GRANT BJ, GUZ A, JONES PW, SEMPLE SJ, STIDWILL RP: Dependence of phrenic motoneurone output on the oscillatory component of arterial blood gas composition. J Physiol 290: 163-184, 1979.

DAHAN A, DEGOEDE J, BERKENBOSCH A, OLIEVIER IC: The influence of oxygen on the ventilatory response to carbon dioxide in man. $J$ Physiol 428: 485-499, 1990.

DAHAN A, NIEUWENHUIJS D, TEPPEMA L: Plasticity of central chemoreceptors: effect of bilateral carotid body resection on central $\mathrm{CO}_{2}$ sensitivity. PLOS Med 4: 1195-1203, 2007.

DUFFIN J: The role of the central chemoreceptors: A modeling perspective. Respir Physiol Neurobiol 173: 230-243, 2010.

FUKUBA Y, KITANO A, HAYASHI N, YOSHIDA T, UEOKA H, ENDO MY, MIURA A: Effects of femoral vascular occlusion on ventilatory responses during recovery from exercise in human. Respir Physiol Neurobiol 155: 29-34, 2007.

GONZALEZ F JR, FORDYCE WE, GRODINS FS: Mechanism of respiratory responses to intravenous $\mathrm{NaHCO}_{3}, \mathrm{HCl}$ and KCN. J Appl Physiol 43: 1075-1079, 1977.

GRIFFITHS TL, HENSON LC, HUNTSMAN D, WASSERMAN K, WHIPP BJ: The influence of inspired $\mathrm{O}_{2}$ partial pressure on ventilator and gas exchange kinetics during exercise. J Physiol 306: 34P, 1980.

HAOUZI P, CHENUEL B, CHALON B, HUSZCZUK A: Distension of venous structures in muscles as a controller of respiration. Frontiers in modeling and control of breathing: integration at molecular, cellular, and systems levels. Adv Exp Med Biol 499: 349-356, 2001.

HAOUZI P, CHENUEL B, CHALON B: Effects of body position on the ventilatory response following an impulse exercise in humans. J Appl Physiol 92: 1423-1433, 2002.

HILDEBRANDT JR, WINN RK, HILDEBRANDT J: Cardiorespiratory responses to sudden release of circulatory occlusion during exercise. Respir Physiol 38: 83-92, 1979.

JONES NL, ROBERTSON DG, KANE JW: Difference between end-tidal and arterial $\mathrm{PCO}_{2}$ in exercise. J Appl Physiol 47: 954-960, 1979.

KAUFMAN MP, LONGHURST JC, RYBICKI KJ, WALLACH JH, MITCHHELL JH: Effects of static muscular contraction on impulse activity of tests III and IV afferents in cats. J Appl Physiol 100: 105-112, 1983.

KNUTTGEN HG, SALTIN B: Muscle metabolites and oxygen uptake in short-term submaximal exercise in man. J Appl Physiol 32: 690-694, 1972.

MCCLOSKEY DI, MITCHELL JH: Reflex cardiovascular and respiratory responses originating in exercising muscle. J Physiol 224: 173-186, 1972.

OREN A, WHIPP BJ, WASSERMAN K: Effect of acid-base status on the kinetics of the ventilatory response to moderate exercise. J Appl Physiol 52: 1013-1017, 1982.

PATERSON DJ: Potassium and ventilation in exercise. J Appl Physiol 72: 811-820, 1992.

PRABHAKAR NR, PENG YJ: Peripheral chemoreceptors in health and disease. J Appl Physiol 96: 359-366, 2004.

SMITH CA, RODMAN JR, CHENUEL JA, HENDERSON KS, DEMPSEY JA: Response time and sensitivity of the ventilatory response to $\mathrm{CO}$ in unanesthetized intact dogs: central vs. peripheral chemoreceptors. $J$ Appl Physiol 100: 13-19, 2006.

STANLEY WC, CHEN JD, LEE WR, BROOKS GA: Ventilatory control studied with circulatory occlusion during exercise recovery. Eur J Appl Physiol 56: 299-305, 1987.

TANSLEY JG, PEDERSEN ME, CLAR C, ROBBINS PA: Human ventilatory response to 8 h of euoxic hypercapnia. J Appl Physiol 84: 431-434, 1998.

TURNER DL: Cardiovascular and respiratory control mechanisms during exercise: An integrated view. J Exp Biol 160: 309-340, 1991.

WASSERMAN K, WHIPP BJ, KOYAL SN, CLEARY MG: Effect of carotid body resection on ventilatory and acidbase control during exercise. J Appl Physiol 39: 354-358, 1975.

WHIPP BJ, WASSERMAN K: Carotid bodies and ventilatory control dynamics in man. Fed Proc 39: 2668-2673, 1980.

ZAVORSKY GS, CAO J, MAYO NE, GABBAY R, MURIAS JM: Arterial versus capillary blood gases: a metaanalysis. Respir Physiol Neurobiol 155: 268-279, 2007. 